\title{
Study the effect of formulation variables in the development of timed-release press-coated tablets by Taguchi design
}

\author{
Chikkanna Narendra ${ }^{1^{*}}$, Mayasandra Srinavasalyengar Srinath ${ }^{2}$ \\ ${ }^{1}$ Department of Pharmaceutics, Visveswarapura Institute of Pharmaceutical Sciences, Bangalore, India; narendragcp@,rediffmail.com \\ ${ }^{2}$ Department of Pharmaceutics, SET'S College of Pharmacy, Dharwad, India
}

Received 30 November 2009; revised 28 December 2009; accepted 3 February 2010.

\begin{abstract}
In this investigation, the effect of formulation variables on the release properties of timedrelease press-coated tablets was studied using the Taguchi method of experimental design. Formulations were prepared based on Taguchi orthogonal array design with different types of hydrophilic polymers $\left(X_{1}\right)$, varying hydrophilic polymer/ethyl cellulose ratio $\left(X_{2}\right)$, and addition of magnesium stearate $\left(X_{3}\right)$ as independent variables. The design was quantitatively evaluated by best fit mathematical model. The results from the statistical analysis revealed that factor $X_{1}, X_{3}$ and interaction factors between $X_{1} X_{2}$ and $X_{1} X_{3}$ were found to be significant on the response lag time $\left(Y_{1}\right)$, where as only factor $X 1$ was found to be significant on the response percent drug release at $8 \mathrm{hrs}\left(Y_{2}\right)$. A numerical optimization technique by desirability function was used to optimize the response variables, each having a different target. Based on the results of optimization study, HPC was identified as the most suitable hydrophilic polymer and incorporation of hydrophobic agent magnesium stearate, could significantly improve the lag time of the timed-release press-coated tablet.
\end{abstract}

Keywords: Press-Coated Tablet; Taguchi Design; Hydrophilic Polymers; Timed-Release; Hydrophobic Agents

\section{INTRODUCTION}

During the recent years timed-release preparations has received increasing attention, which release the drug rapidly and completely after a lag time following oral drug administration. This type of delivery system is not only rate controlled but also time and /or site controlled to deliver the drug when it is required. Such time and/or site controlled formulations has been widely investigated for a number of diseases and therapies $[1,2]$.

Over a period, many different approached have been used for delivering the drugs as time and /or site specific which includes, Timeclock ${ }^{\circledR}$ system [3], Chronotropic ${ }^{\circledR}$ system [4], Pulsincap ${ }^{\circledR}$ sysem [5], Port ${ }^{\circledR}$ system [6], TimeRx ${ }^{\circledR}$ system [7] and Geomatrix ${ }^{\circledR}$ system [8]. These systems are developed with intention to meet the needs of chronopathologies with symptoms mostly recurring at night time or early morning hours. The principal advantage of Chronotherapeutic drug delivery system includes consideration of a person's biological rhythms in determining the timing and the amount of medication to optimize a drug's desired effects and minimize the undesired ones. As a consequence there is reduction of dose requirement and this likely to improve patient compliance [9].

In spite of the difficulties faced by releasing actives due to the variable gastrointestinal environment, orally administered timed-release delivery systems are most preferred because they offer flexibility in dosage-form design and are relatively safe. Press-coated tablet composed of an inner core that contains an active pharmaceutical ingredient and inert excipients surrounded by an outer coating layer. The outer coating material may be compressed onto the inner core as compression coated which dissolves or erodes or disintegrates slowly to produce a lag time before the release of active ingredient.

Several types of hydrophilic polymers have been investigated as a compression coating material including hydroxypropylmethylcellulose [10], L-hydroxypropylcellulose [11], hydroxyethylcellulose [12], polyethyleneoxide/polyethyleneglycol [13], and pectin/ hydroxypropylmethylcellulose [14]. Lin et al. [15] studied the effect of hydrophilic excipients (spray-dried lactose and HPMC K4M) along with hydrophobic ethylcellulose as an outer coating shell material and concluded that addition of hydrophilic excipients can be very useful in controlling the lag time adequately. The effect of hydroxyl- 
propylmethylcellulose acetate succinate (HPMCAS) and water soluble/insoluble plasticizers-adsorbent as outer coating material was reported by Fukui et al. [16] and the results suggested that the outer shell had a plastic deformation property due to some interaction between HPMCAS and water soluble plasticizers-adsorbent and the same would be useful for colon targeting. In another study, effect of hydrophobic additives were investigated and the results indicated that mixing of HPMCAS, magnesium stearate and calcium stearate at appropriate ratio prolonged the lag time [17].

Design of experiment has been widely used in pharmaceutical field to study the effect of formulation variables and their interaction on dependent (response) variables. [18-20] In the present study an attempt is made to study the effect of formulation variables with the aid of Taguchi design to identify the potential contribution of various types of hydrophilic polymers, varying the hydrophilic/ethylcellulose ratio and presence and absence of magnesium stearate.

\section{MATERIALS AND METHODS}

\subsection{Materials}

Theophylline anhydrous was received as gift sample from M/s Eros Pharma Pvt. Ltd., Bangalore, India. Hydroxypropylmethylcllulose (HPMC, Methocel K100M), sodium carboxymethylcellulose (NaCMC, HVP), Hydroxypropylcellulose (HPC, Klucel ${ }^{\circledR}$ EXF Pharm), Hydroxyethylcellulose (HEC, NATROSOL ${ }^{\circledR} 250$ HX Pharm) and ethylcellulose (EC, Ethocel ${ }^{\circledR} 25 \mathrm{cPs}$ ) were supplied by M/s Strides Arco, Labs Ltd., Bangalore, India as gift samples. Other materials were purchased from commercial source; magnesium stearate (Loba chemicals, Mumbai, India), polyvinylpyrrolidine (PVP K30) (Reidel India chemicals, Mumbai, India), sodium starch glycolate, talc (Nice chemicals, Cochin, India) and directly compressible lactose (S.D. fine chemicals Ltd, Mumbai, India). All other chemicals used in the study were of analytical grade.

\subsection{Experimental Design}

A Taguchi design $\left[\mathrm{L}_{16}\left(4^{5}\right)\right]$ was implanted to study the effect of formulation variables in the development of timed release press-coated tablet. The Taguchi method utilizes orthogonal arrays are essentially fractional factorial experimental design to study the large number of variables with a small number of experiments. Generally a full factorial design would yield large experiments with replication of centre points.

The levels of the 3 independent variables are as follows;

$\mathrm{X}_{1}=$ Type of Hydrophillic polymer (HPMC, NaCMC, HPC and HEC)

$\mathrm{X}_{2}=$ Hydrophilic polymer/EC (1:1 to $\left.4: 1\right)$
$\mathrm{X}_{3}=$ Amount of magnesium stearate (0 to $10 \%$ )

The response variables tested include:

$\mathrm{Y}_{1}=\mathrm{Lag}$ time (time required for $10 \%$ of drug release in hour)

$\mathrm{Y}_{2}=$ Percent drug release at $8 \mathrm{hrs}$.

\subsection{Preparation of Core Tablet}

A direct compression method was adapted to prepare the core tablet. As shown in Table 1, Theophylline anhydrous, lactose, PVP K30 and sodium starch glycolate were mixed in a suitable stainless steel vessel in a tumbler mixer (Rimek, Karnavati Engineering Ltd. Ahmedabad, India) at $100 \mathrm{rpm}$ for $30 \mathrm{~min}$. thoroughly after passing through 80 mesh screen. Further, magnesium stearate and talc were added to the above powder mixture and blended for $10 \mathrm{~min}$. Finally the resulting powder blend was compressed by using a 10-station rotary tablet compression machine (Rimek, Ahmedabad, India) fitted with $8 \mathrm{~mm}$ standard concave punches. Preparation was performed in 100 tablet batches and compression was controlled to produce $4 \pm 0.5 \mathrm{~kg} / \mathrm{cm}^{2}$ tablet crushing strength.

\subsection{Preparation of Press-Coated Tablet}

The formulations were prepared at random following Taguchi design. Prior to compression all the ingredients were passed through 80 mesh screen. The core tablets were press-coated with an appropriate blend of polymers with or with out magnesium stearate as given in Table 2. Half the quantity of outer coating material was weighed and transferred into the die; manually the core tablet was placed carefully in the centre of the die. Then, the remaining half quantity of outer coating material was added into the die and compressed by using 10-station rotary tablet compression machine (Rimek, Ahmedabad, India) fitted with $11 \mathrm{~mm}$ standard concave punches and compression was controlled to produce $14 \pm 0.5 \mathrm{~kg} / \mathrm{cm}^{2}$ tablet crushing strength.

\subsection{In Vitro Dissolution Studies}

The dissolution was performed by using USP dissolution apparatus II paddle assembly (TDT-06T, Electrolab, India) at $37^{\circ} \mathrm{C} \pm 1{ }^{\circ} \mathrm{C}$ using $750 \mathrm{ml}$ of $\mathrm{pH} 1.2$ buffer for the first 2 hours and followed by $900 \mathrm{ml}$ of $\mathrm{pH} 6.8$ buffer till the end of dissolution studies. The paddle rotational speed was set to $100 \mathrm{rpm}$. Aliquots samples were withdrawn at specified time intervals and the samples were

Table 1. Composition of core layer of press-coated tablet.

\begin{tabular}{cc}
\hline Ingredients & $\begin{array}{c}\text { Quantity } \\
(\mathbf{m g} / \mathbf{t a b l e t})\end{array}$ \\
\hline Theophylline anhydrous & 100 \\
Sodium starch glycolate & 10 \\
Polyvinylpyrrolidone & 5 \\
Magnesium stearate & 1 \\
Talc & 2 \\
Lactose & 32 \\
\hline
\end{tabular}


Table 2. Composition of coat layer of press-coated tablets based on Taguchi design with observed responses.

\begin{tabular}{cccccc}
\hline $\begin{array}{c}\text { Formula- } \\
\text { tion code }\end{array}$ & $\begin{array}{c}\mathbf{X}_{\mathbf{1}} \\
\text { Type }\end{array}$ & $\begin{array}{c}\mathbf{X}_{\mathbf{2}} \\
\text { Ratio }\end{array}$ & $\begin{array}{c}\mathbf{X}_{\mathbf{3}} \\
\mathbf{( \% )}\end{array}$ & $\begin{array}{c}\mathbf{Y}_{\mathbf{1}} \\
\mathbf{( H r})\end{array}$ & $\begin{array}{c}\mathbf{Y}_{\mathbf{2}} \\
(\mathbf{\%})\end{array}$ \\
\hline F1 & HPMC & $1: 1$ & 0 & $5.3 \pm 0.6$ & $10.51 \pm 2.01$ \\
F2 & HPMC & $2: 1$ & 10 & $7.5 \pm 0.5$ & $10.05 \pm 3.16$ \\
F3 & HPMC & $3: 1$ & 0 & $3.4 \pm 0.3$ & $12.30 \pm 2.37$ \\
F4 & HPMC & $4: 1$ & 10 & $7.1 \pm 0.5$ & $42.40 \pm 1.15$ \\
F5 & NaCMC & $1: 1$ & 0 & $1.4 \pm 1.1$ & $100^{*}$ \\
F6 & NaCMC & $2: 1$ & 10 & $3.1 \pm 1.6$ & $100^{*}$ \\
F7 & NaCMC & $3: 1$ & 0 & $2.5 \pm 0.9$ & $100^{*}$ \\
F8 & NaCMC & $4: 1$ & 10 & $4.2 \pm 0.7$ & $98.14 \pm 3.34$ \\
F9 & HPC & $1: 1$ & 10 & $5.5 \pm 0.5$ & $100.81 \pm 4.22$ \\
F10 & HPC & $2: 1$ & 0 & $2.3 \pm 1.3$ & $103.68 \pm 3.14$ \\
F11 & HPC & $3: 1$ & 10 & $7.1 \pm 0.5$ & $98.87 \pm 4.06$ \\
F12 & HPC & $4: 1$ & 0 & $2.8 \pm 1.0$ & $114.87 \pm 4.13$ \\
F13 & HEC & $1: 1$ & 10 & $4.6 \pm 0.3$ & $14.13 \pm 4.05$ \\
F14 & HEC & $2: 1$ & 0 & $2.5 \pm 0.9$ & $14.32 \pm 3.55$ \\
F15 & HEC & $3: 1$ & 10 & $5.2 \pm 0.6$ & $11.98 \pm 3.22$ \\
F16 & HEC & $4: 1$ & 0 & $2.6 \pm 0.5$ & $16.05 \pm 3.37$ \\
\hline
\end{tabular}

$* 100 \%$ drug release was observed before $8 \mathrm{hrs}$ of dissolution studies.

analyzed spectrophotometrically (UV-1601, Shimadzu, Japan) at $271 \mathrm{~nm}$ and the amount of drug released was determined from the calibration curve. The volume of the sample withdrawn each time was replaced with the same volume of the respective buffer solution. The studies were carried out in triplicate and mean values plotted verses time with standard error of mean, indicating the reproducibility of the results.

\subsection{Statistical Analysis}

The effect of formulation variables on the response variables were statically evaluated by applying one-way ANOVA at 0.05 level using a commercially available software package Design-Expert ${ }^{\mathbb{B}}$ version 6.05 (StatEase, Inc.). The design was evaluated by using a suitable model. The best fit model was selected based on the several statistical parameters including multiple correlation coefficient $\left(\mathrm{R}^{2}\right)$, adjusted multiple correlation coefficient (adjusted $\mathrm{R}^{2}$ ) and the predicted residual sum of square (PRESS). For the model to be chosen as best fit, the PRESS valve should be small relative to the other models.

\section{Linear model}

$\mathrm{Y}=\mathrm{b}_{0}+\mathrm{b}_{1} \mathrm{X}_{1}+\mathrm{b}_{2} \mathrm{X}_{2}+\mathrm{b}_{3} \mathrm{X}_{3}$

Two factor interaction model

$\mathrm{Y}=\mathrm{b}_{0}+\mathrm{b}_{1} \mathrm{X}_{1}+\mathrm{b}_{2} \mathrm{X}_{2}+\mathrm{b}_{3} \mathrm{X}_{3}+\mathrm{b}_{4} \mathrm{X}_{1} \mathrm{X}_{2}+\mathrm{b}_{5} \mathrm{X}_{1} \mathrm{X}_{3}+\mathrm{b}_{6} \mathrm{X}_{2} \mathrm{X}_{3}$ where $\mathrm{Y}$ is the response variable, $\mathrm{b}_{0}$ the constant and $\mathrm{b}_{1}$, $b_{2}, b_{3}, \ldots, b_{5}$ is the regression coefficient. $X_{1}, X_{2}$ and $X_{3}$ stand for the main effect; $\mathrm{X}_{1} \mathrm{X}_{2}, \mathrm{X}_{1} \mathrm{X}_{3}$ and $\mathrm{X}_{2} \mathrm{X}_{3}$ are the interaction terms, show how response changes when two factors are simultaneously changed.

\section{RESULT AND DISCUSSION}

\subsection{Experimental Design}

Taguchi method as design of experiment was chosen for the organization of the experiments and analysis of the results. Normally a full factorial design for such experiment would yield $4 \times 4 \times 2=32$ experiments. In the present case, $\mathrm{L}_{16}$ orthogonal array, a mixed-level design ( 2 factors at 4 levels and one factor at 2 levels) was considered and the size of experimentation was represented by symbolic arrays i.e. 16 experiments [21]. The use of more than two factors makes it possible to study some of the eventual non-linear effects with interactions between the factors. The statistical analysis to select the model that best fits the data was obtained by analyzing the results of sequential model given in the Table 3. As seen from the table, though the linear model was found to be significant but the PRESS value for a two factor interaction model (2FI) was found to be least hence, 2FI model was considered to analyze the response lag time. For the response percent drug release at $8 \mathrm{hrs}$, linear model was found be significant with low PRESS value and the same model was further navigated for ANOVA studies.

\subsection{Effect of Type of Hydrophilic Polymers}

Figures 1-4 show the release profile of press-coated tablets in accordance to type of hydrophilic polymer. If HPMC as type of hydrophilic polymer, increasing the amount of HPMC in the coating layer, formulations F1, F2 and F3 exhibited a minimal drug release at the end of dissolution studies. Such a type of decrease in drug release may be due to increased amount of EC in the coating layer retarded the rate of hydration of HPMC which

Table 3. Comparison of sequential model.

\begin{tabular}{ccccccc}
\hline \multirow{2}{*}{$\begin{array}{c}\text { Statistical } \\
\text { Parameters }\end{array}$} & \multicolumn{3}{c}{$\mathbf{Y}_{\mathbf{1}} \mathbf{( h r )}$} & \multicolumn{3}{c}{$\mathbf{Y}_{\mathbf{1}} \mathbf{( \% )}$} \\
\cline { 2 - 7 } & Linear & $2 F I$ & Quadratic & Linear & $2 F I$ & Quadratic \\
\hline $\mathrm{R}^{2}$ & 0.8754 & 0.9940 & 0.9941 & 0.9773 & 0.9910 & 0.9953 \\
Adjusted R & 0.8132 & 0.9704 & 0.9558 & 0.9660 & 0.9550 & 0.9648 \\
PRESS & 16.11724 & $\mathbf{9 . 2 9 7 7}$ & 20.88 & $\mathbf{1 9 0 7 . 0 3 3}$ & 7752.664 & 9088.802 \\
p Valve & $\mathbf{0 . 0 0 0 3 *}^{2}$ & 0.0522 & 0.9563 & $\mathbf{< . 0 0 0 1 *}$ & 0.713 & 0.3079 \\
\hline
\end{tabular}

* denotes significant $\mathrm{p}<0.05$. 


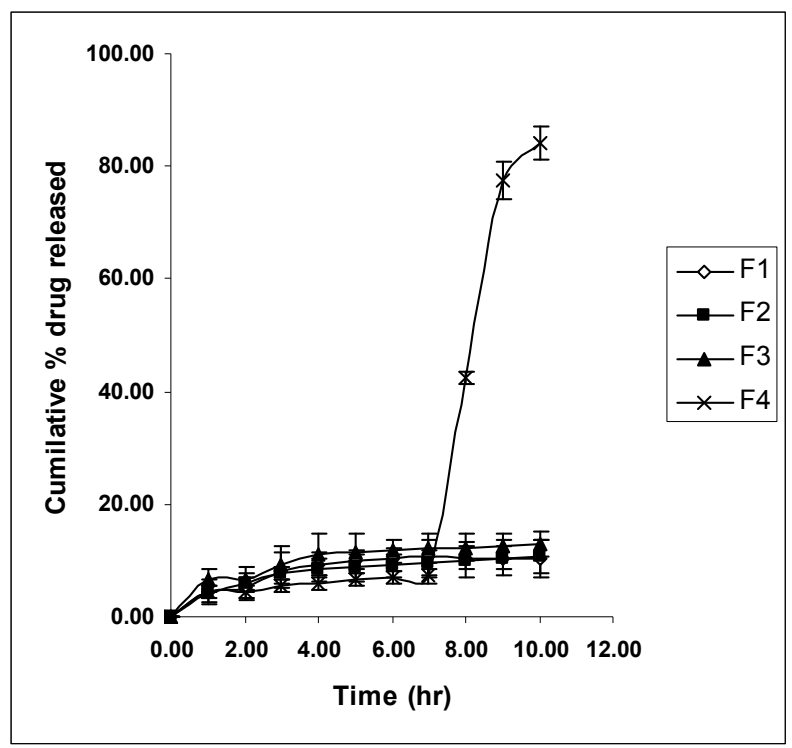

Figure 1. Dissolution profiles of press-coated tablets containing HPMC as type of hydrophilic polymer.

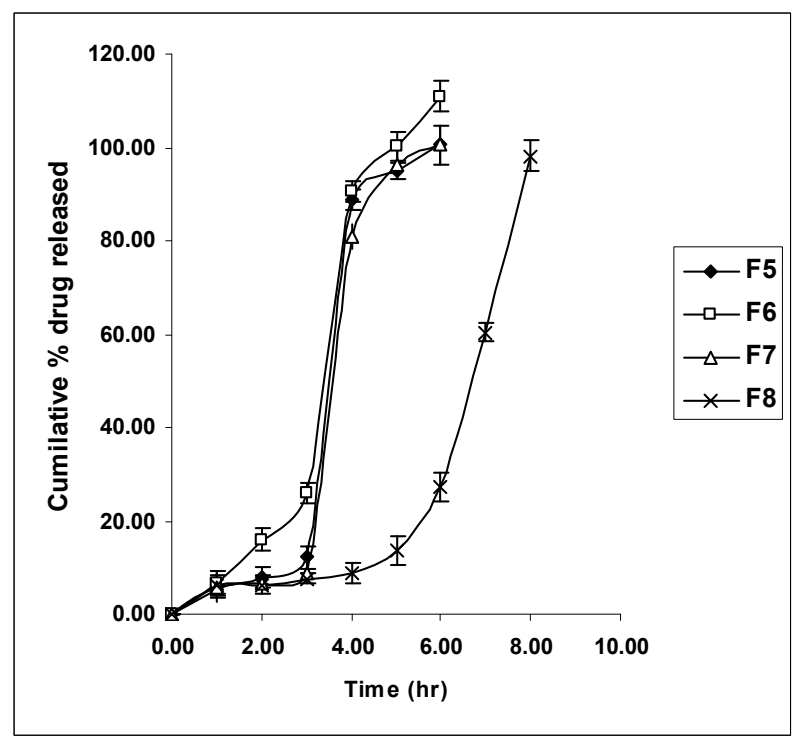

Figure 2. Dissolution profiles of press-coated tablets containing $\mathrm{NaCMC}$ as type of hydrophilic polymer.

in turn hindered the drug release. In case of formulation $\mathrm{F} 4$, the release from the tablet was more in a sustained manner than a burst release which may be due to slower hydration of HPMC and also this formulation contains least amount of $\mathrm{EC}$ than the other formulations of HPMC.

Similar but opposite result was observed in case of $\mathrm{NaCMC}$, that all the formulations show a relative, slow initial drug release for first 2 hours then the release increases quickly to $100 \%$ with in 8 hours of dissolution studies. This behavior of increase in drug release may be

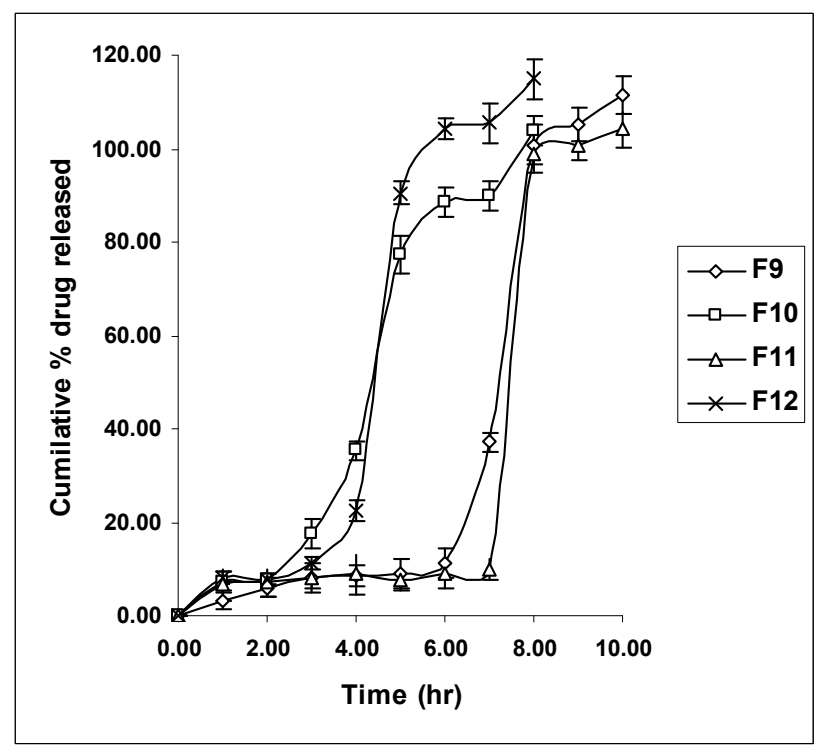

Figure 3. Dissolution profiles of press-coated tablets containing HPC as type of hydrophilic polymer.

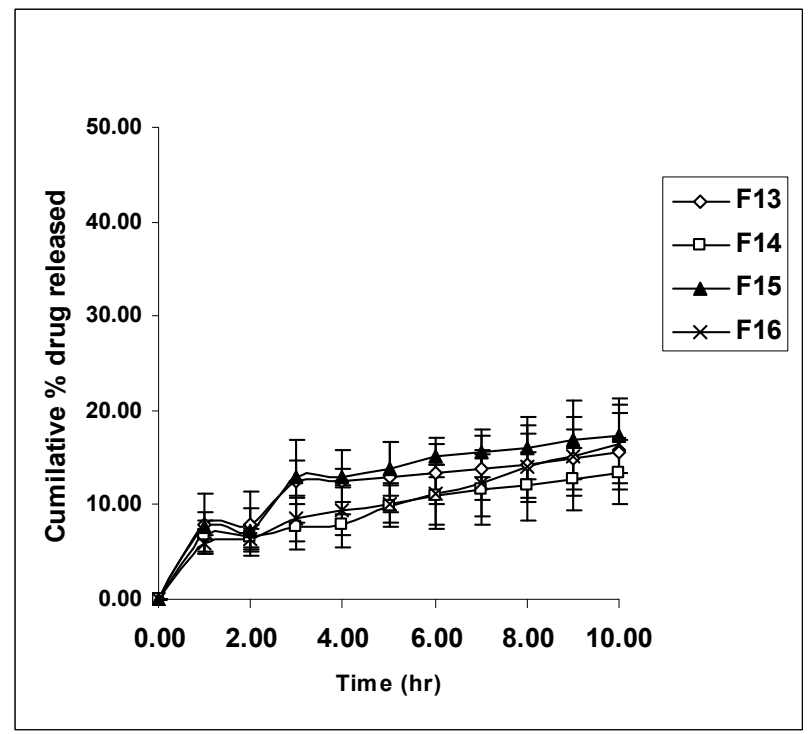

Figure 4. Dissolution profiles of press-coated tablets containing HEC as type of hydrophilic polymer.

due to high solubility of $\mathrm{NaCMC}$ at $\mathrm{pH} 6.8$ [22] also this polymer undergoes a quick gel erosion rate and complete disintegration of polymer matrix. In case of HPC as type of hydrophilic polymer, the dissolution behavior was characterized by sigmoid, S-shaped curve release profile with a prolonged lag time and a complete drug release from the core tablet was observed at the end of dissolution studies due to separation of coating layer into two halves allowing the core tablet exposed to dissolution medium (observation made during the dissolution studies). HEC as a type of hydrophilic polymer, the release 
at the end of dissolution studies were found to be less than $18 \%$ which may be due to high viscosity of polymer, decreased water uptake to form a gel matrix [23] and presence of hydrophobic components such as EC and magnesium stearate further prevented the hydration rate.

\subsection{Effect of Hydrophilic/EC Ratio}

EC, a cellulose ether derivative most widely used as water insoluble polymer for coating of solid dosage forms. Besides as controlled release barrier, they have also been used as moisture barrier to improve stability of hydrolytically liable drugs [24]. The effect of hydrophilic/EC ratio in presence and absence of magnesium stearate on the release properties are summarized in Table 4. On comparison of values, increasing the hydrophilic/EC ratio, HPMC containing formulations exhibited a negative effect on lag time where as a positive effect was observed in case of other hydrophilic polymers. HPMC and HEC containing formulations showed no complete drug release from the tablet even at the end of dissolution studies which is probably due to slow hydration rate (because of hydrophobic components) and also the hydrogel layer therefore formed was strong enough and could inhibit further water penetration into the inside of core tablet $[25,26]$.

In case of NaCMC and HPC, they did not show significant difference in their release profile at the end of dissolution studies except that $\mathrm{NaCMC}$ containing formulations exhibited shorter lag time with complete drug release with in 8 hours of dissolution studies where as in case of HPC containing formulations exhibited longer lag time with complete drug release at the end of dissolution studies. Such a type of release behavior may be due to faster hydration followed by a combination of disintegration and high erosion rate for the former where as moderate swelling with low erosion rate for the later [26,27].

\subsection{Effect of Magnesium Stearte}

The effect of magnesium stearate on the lag time and percent drug release at $8 \mathrm{hrs}$ can be visualized from the Table 4. The formulations containing magnesium stearate exhibited an improved lag time but no improvement was observed in case of percent drug release at $8 \mathrm{hrs}$. The beneficial effect of magnesium stearate on the lag time is probably due to its hydrophobic nature prolongs the lag time by significantly decreasing the water uptake

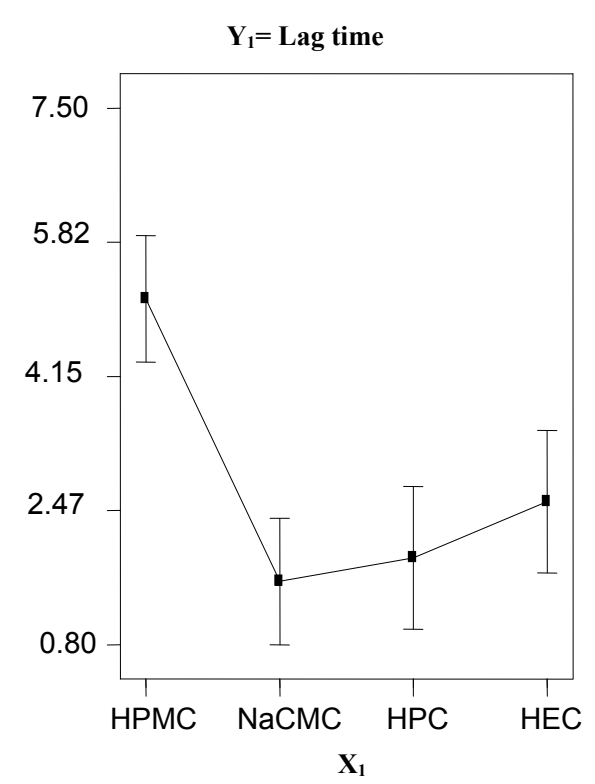

Figure 5. Main effect plot for type of hydrophilic polymer $\left(\mathrm{X}_{1}\right)$ on lag time $\left(\mathrm{Y}_{1}\right)$ by keeping factors $\mathrm{X}_{2}$ and $\mathrm{X}_{3}$ at lower level.

and penetration through the coating layer [28].

\subsection{Statistical Analysis}

The model terms for $\mathrm{Y}_{1}$ (lag time) were found to be significant with an $F$ value of $42.10(0.0052)$, high $\mathrm{R}^{2}$ value of 0.9940 indicate the adequate fitting of two factor interaction model. As shown in Table 5, factors $X_{1}, X_{3}$ and interaction factors $\mathrm{X}_{1} \mathrm{X}_{2}$ and $\mathrm{X}_{1} \mathrm{X}_{3}$ were found to be significant.

At lower level of factors $\mathrm{X}_{2}$ and $\mathrm{X}_{3}$, changing the type of hydrophilic polymer from HPMC to HEC the lag time decreases but at higher level of factors $\mathrm{X}_{2}$ and $\mathrm{X}_{3}$, the lag time increased to a greater value if HPMC and HPC were used as the type of hydrophilic polymer, where as in case of $\mathrm{NaCMC}$ and HEC the effect was found to be negative (Figures $5 \&$ 6).

Changing the factor $\mathrm{X}_{3}$ from lower to higher level, a significant positive effect on the lag time was observed with irrespective of type of hydrophilic polymer and hydrophilic /EC ratio.

The interaction effect between the factors $X_{1} X_{2}$ can be studied with the help of Figures $7 \& 8$.

In presence or absence of magnesium stearate, if $\mathrm{X}_{2}$ was increased from lower to higher level and by

Table 4. Comparison of release parameters prepared from different types of hydrophilic polymers.

\begin{tabular}{|c|c|c|c|c|c|c|c|c|}
\hline \multirow{2}{*}{ Response } & \multicolumn{2}{|c|}{ HРMC } & \multicolumn{2}{|c|}{$\mathrm{NaCMC}$} & \multicolumn{2}{|c|}{ HPC } & \multicolumn{2}{|c|}{ HEC } \\
\hline & ${ }^{1}$ no MgSt & ${ }^{2} \mathrm{MgSt}$ & ${ }^{3}$ no MgSt & ${ }^{4} \mathrm{MgSt}$ & ${ }^{5}$ no MgSt & ${ }^{6} \mathrm{MgSt}$ & ${ }^{7}$ no MgSt & ${ }^{8} \mathrm{MgSt}$ \\
\hline $\mathrm{Y}_{1}(\mathrm{Hr})$ & 4.35 & 7.3 & 1.95 & 3.65 & 2.55 & 6.3 & 2.55 & 4.9 \\
\hline$Y_{2}(\%)$ & 11.405 & 26.229 & 100 & 99.07 & 109.275 & 99.84 & 15.185 & 13.055 \\
\hline
\end{tabular}

Mean values from the formulations ${ }^{1} \mathrm{~F} 1-\mathrm{F} 3,{ }^{2} \mathrm{~F} 2-\mathrm{F} 4,{ }^{3} \mathrm{~F} 5-\mathrm{F} 7,{ }^{4} \mathrm{~F} 6-\mathrm{F} 8,{ }^{5} \mathrm{~F} 10-\mathrm{F} 12,{ }^{6} \mathrm{~F} 9-\mathrm{F} 11,{ }^{7} \mathrm{~F} 14-\mathrm{F} 16,{ }^{8} \mathrm{~F} 13-\mathrm{F} 15$. 
Table 5. Summary of ANOVA table for dependent variables from Taguchi design.

\begin{tabular}{|c|c|c|c|c|c|}
\hline Source & d.f. & Sum square & Mean square & F value & Probability \\
\hline $\mathrm{Y}_{1}(\mathrm{Hr})$ & & & & & $\mathrm{R}^{2}=0.9940$ \\
\hline Model & 12 & 55.04 & 4.59 & 42.10 & $0.0052 *$ \\
\hline $\mathrm{X}_{1}$ & 3 & 19.29 & 6.43 & 59.01 & $0.0036^{*}$ \\
\hline $\mathrm{X}_{2}$ & 1 & 0.46 & 0.46 & 4.18 & 0.1334 \\
\hline $\mathrm{X}_{3}$ & 1 & 26.34 & 26.34 & 241.70 & $0.0006^{*}$ \\
\hline $\mathrm{X}_{1} \mathrm{X}_{2}$ & 3 & 3.30 & 1.10 & 10.10 & $0.0446 *$ \\
\hline $\mathrm{X}_{1} \mathrm{X}_{3}$ & 3 & 4.38 & 1.46 & 13.41 & $0.0304^{*}$ \\
\hline $\mathrm{X}_{2} \mathrm{X}_{3}$ & 1 & 0.60 & 0.60 & 5.51 & 0.1005 \\
\hline$Y_{2}(\%)$ & & & & & $\mathrm{R}^{2}=0.9773$ \\
\hline Model & 5 & 29611.65 & 5922.33 & 86.34 & $<0.0001 *$ \\
\hline $\mathrm{X}_{1}$ & 3 & 29388.78 & 9796.26 & 142.82 & $<0.0001^{*}$ \\
\hline $\mathrm{X}_{2}$ & 1 & 221.52 & 221.52 & 3.23 & 0.1025 \\
\hline $\mathrm{X}_{3}$ & 1 & 1.36 & 1.36 & 0.02 & 0.8910 \\
\hline
\end{tabular}

d.f. denotes degree of freedom; * denotes significant $\mathrm{p}<0.05$.

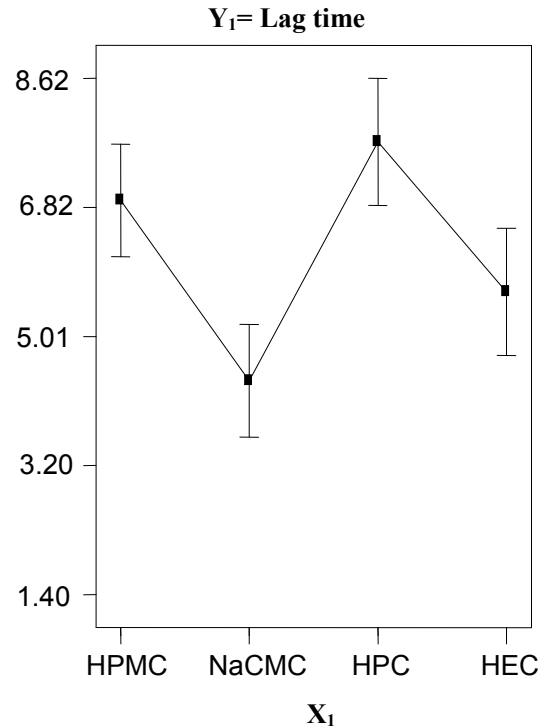

Figure 6. Main effect plot for type of hydrophilic polymer $\left(\mathrm{X}_{1}\right)$ on lag time $\left(\mathrm{Y}_{1}\right)$ by keeping factors $\mathrm{X}_{2}$ and $\mathrm{X}_{3}$ at higher level.

changing the type of hydrophilic polymer, only HPMC containing formulations showed negative effect where as other hydrophilic polymers showed positive effect on the lag time.

The interaction effect between the factors $X_{1} X_{3}$ can be studied with the help of Figures $9 \& \mathbf{1 0}$.

From this figures it may be concluded that presence of magnesium stearate in the coating layer exhibited a positive effect on the lag time with irrespective levels of factors $\mathrm{X}_{1}$ and $\mathrm{X}_{2}$.

A linear model for $\mathrm{Y}_{2}$ (percentage drug release at $8 \mathrm{hrs}$ ) was found to be significant. In this case, only factor $\mathrm{X}_{1}$ was found to be significant (Table 5). As the factor $\mathrm{X}_{1}$ was increased from lower to higher level, $\mathrm{NaCMC}$ and

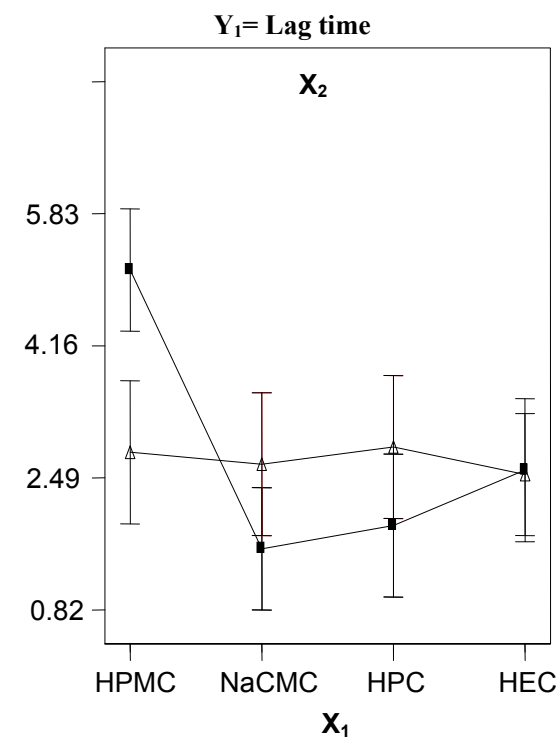

Figure 7. Interaction effect plot between type of hydrophilic polymer $\left(\mathrm{X}_{1}\right)$ and hydrophilic polymer/EC ratio $\left(\mathrm{X}_{2}\right)$ on lag time $\left(\mathrm{Y}_{1}\right)$ at lower level of factor $\mathrm{X}_{3}$. (• Lower level; $\Delta$ Higher level).

HPC containing formulations exhibited an increased amount of drug release where as incase of HPMC and HEC containing formulations exhibited very less amount of drug release (Figures $11 \&$ 12). This type of behavior may be attributed due to low hydration rate of these polymers in presence to EC and magnesium stearate and if so hydrated they formed a dense layer which further decreases the water diffusion into the core layer and delayed the release of drug from the dosage form [29].

\section{OPTIMIZATION}

To optimize the studied responses with different targets, 


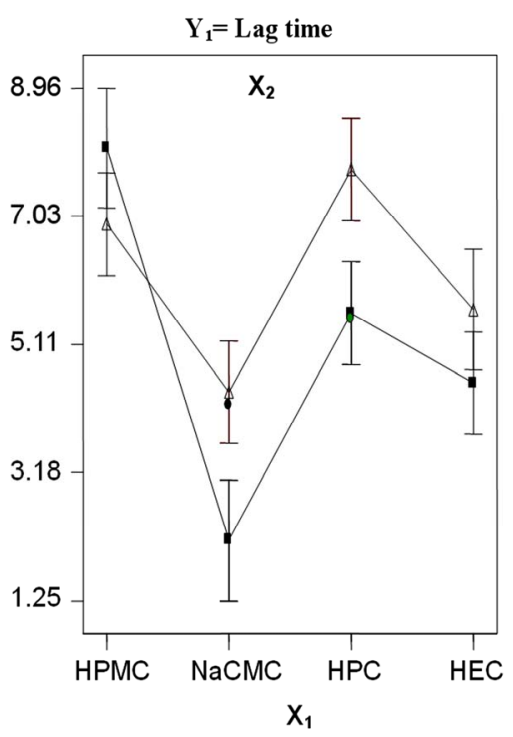

Figure 8. Interaction effect plot between type of hydrophilic polymer $\left(\mathrm{X}_{1}\right)$ and hydrophilic polymer/EC ratio $\left(\mathrm{X}_{2}\right)$ on lag time $\left(\mathrm{Y}_{1}\right)$ at higher level of factor $\mathrm{X}_{3}$. (Lower level; $\Delta$ Higher level).

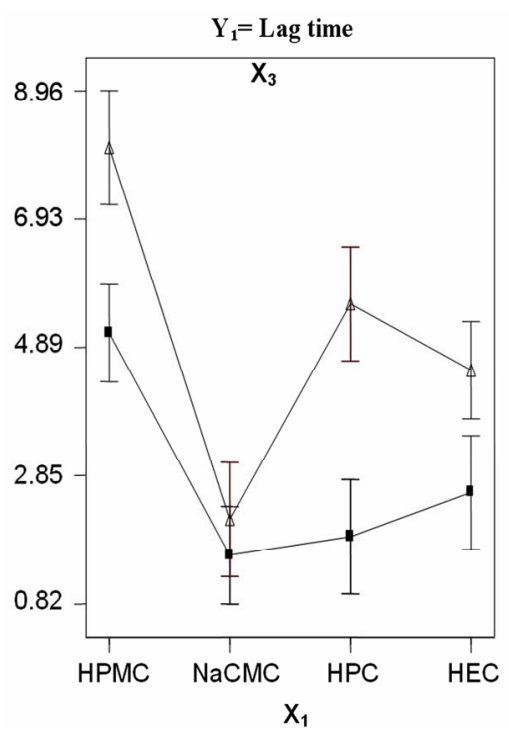

Figure 9. Interaction effect plot between type of hydrophilic polymer $\left(\mathrm{X}_{1}\right)$ and amount of magnesium stearate $\left(\mathrm{X}_{3}\right)$ on lag time $\left(\mathrm{Y}_{1}\right)$ at lower level of factor $\mathrm{X}_{2}$. $($ Lower level; $\Delta$ Higher level).

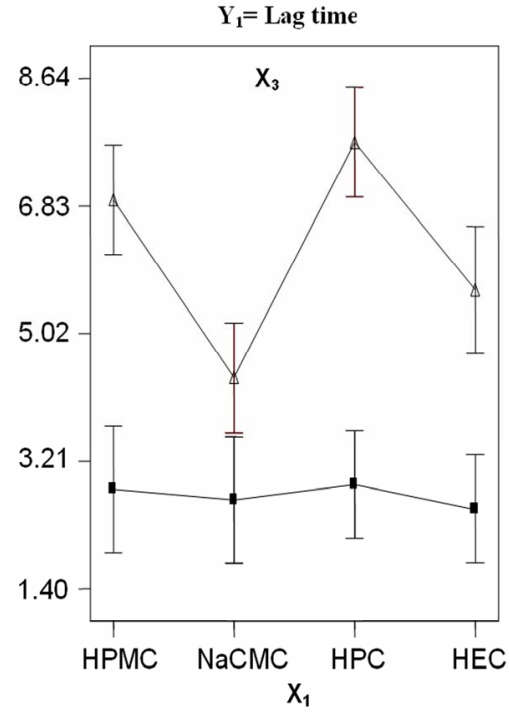

Figure 10. Interaction effect plot between type of hydrophilic polymer $\left(\mathrm{X}_{1}\right)$ and amount of magnesium stearate $\left(\mathrm{X}_{3}\right)$ on lag time $\left(\mathrm{Y}_{1}\right)$ at higher level of factor $\mathrm{X}_{2}(\cdot$ Lower level; $\Delta$ Higher level).

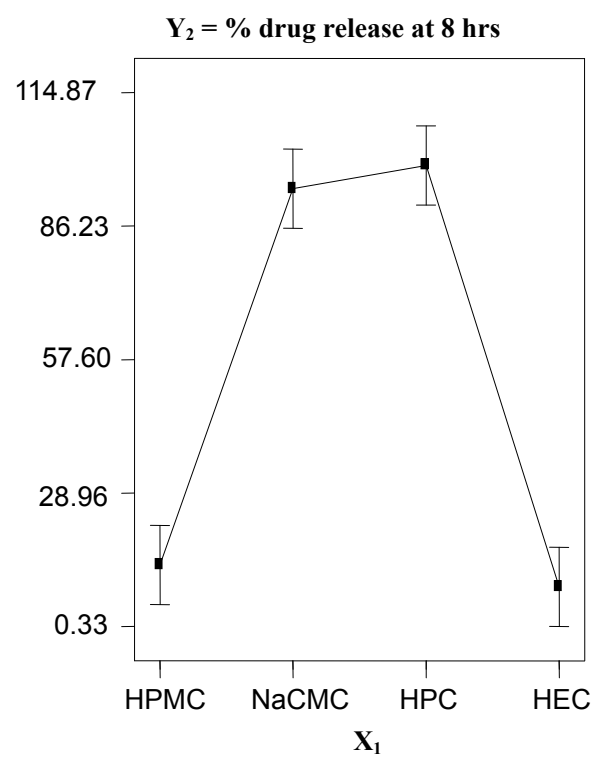

Figure 11. Main effect plot for type of hydrophilic polymer $\left(\mathrm{X}_{1}\right)$ on \% drug release at $8 \mathrm{hrs}\left(\mathrm{Y}_{2}\right)$ by keeping factors $\mathrm{X}_{2}$ and $\mathrm{X}_{3}$ at lower level.

a multi-criteria decision approach, like numerical optimization technique by the desirability function was used to generate the optimum settings for the formulation. [30, 31] The variables were optimized for the response $Y_{1}$ and $Y_{2}$ and the optimized formulation settings were arrived by maximizing the percent drug release at $8 \mathrm{hrs}$ and lag time was kept at range between 6 to 7 hours. According to the statistical prediction, the optimal values obtained

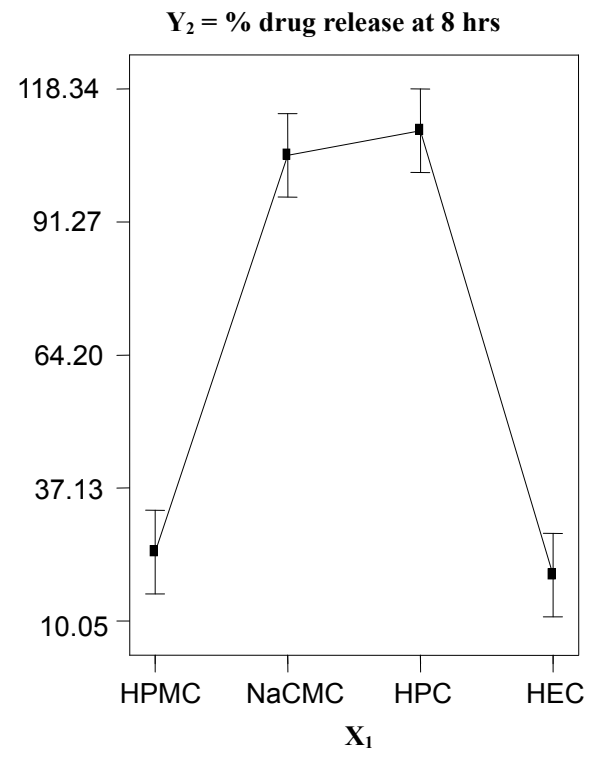

Figure 12. Main effect plot for type of hydrophilic polymer $\left(\mathrm{X}_{1}\right)$ on $\%$ drug release at $8 \mathrm{hrs}\left(\mathrm{Y}_{2}\right)$ by keeping factors $\mathrm{X}_{2}$ and $\mathrm{X}_{3}$ at higher level.

was: HPC for type of hydrophilic polymer, hydrophilic polymer/EC ratio ranged between 2.5: 1 to $4: 1$ and magnesium stearate also was ranged between $26-30 \mathrm{mg}$. Since, the Taguchi design is used to screen the formulation variables and to study their significant effect [32], the results from optimization studies was found to be in wider range and suggesting further studies to arrive to the optimal settings. 


\section{CONCLUSIONS}

A Taguchi design was performed to screen the effect of formulation variables on the response lag time and percent drug release at $8 \mathrm{hrs}$ in the development of timedrelease press-coated tablets by applying computer optimization technique. Type of hydrophilic polymer was found to be the major factor affecting studied responses and also the results demonstrated that the hydrophobic agent, magnesium stearate could significantly prolonged the lag time. Among the type of different hydrophilic polymers studied, HPC was found to be more suitable and other hydrophilic polymers did not demonstrate beneficial effect (with in the studied variable limits) in the development of timed-release press-coated tablets. Based on the results of optimization studies it was concluded that further studies are required to obtain the optimal settings.

\section{REFERENCES}

[1] Ueda, S., Hata, T., Asakura, S., Yamaguchi, H., Kotani, M. and Ueda, Y. (1994) Development of a novel drug release system, time-controlled explosion system (TES). I. Concept and design. Journal of Drug Targeting, 2(1), 35-44.

[2] Krögel, I. and Bodmeier, R. (1998) Pulsatile drug release from an insoluble capsule body controlled by an erodible plug. Pharmaceutical Research, 15(3), 474-481.

[3] Pozzi, F., Furlani, P., Gazzaniga, A., Davis, S.S. and Wilding, I.R. (1994) The TIME CLOCK* system: A new oral dosage form for fast and complete release of drug after a predetermined lag time. Journal of Controlled Release, 31(1), 99-108.

[4] Gazzaniga A., Sangalli, M. and Giordano, F. (1994) Oral chronotropic drug delivery systems: Achievement of time and/or site specificity. European Journal of Pharmaceutics and Biopharmaceutics, 40, 246-250.

[5] McNeil, M.E., Rashid, A. and Stevens, H.N.E. (1994) Dispensing device. U.S. Patent 5,342,624.

[6] Crison, J.R., Siersma, P.R., Taylor, M.D. and Amidon, G.L. (1995) Programmable oral release technology, Port Systems \& Mac226: A novel dosage form for time and site specific oral drug delivery. Proceedings of International Symposium on Control Release of Bioactive Materials, 22, 278-279.

[7] Conte, U., Maggi, L., Torre, P., Giunchedi, P. and La-Manna, A. (1993) Press-coated tablets for time programmed release of drugs. Biomaterials, 14(13), 10171023.

[8] Conte, U. and Maggi, L. (1996) Modulation of the dissolution profiles from Geomatrix ${ }^{\circledR}$ multi-layer matrix tablets containing drugs of different solubility. Biomaterials, 17(9), 889-896.

[9] Lemmer, B. (2007) Chronobiology, drug-delivery, and chronotherapeutics. Advanced Drug Delivery Reviews, 59(9-10), 825-827.

[10] Wu, B., Shun, N., Wei, X. and Wu, W. (2007) Characterization of 5-fluorouracil release from hydroxypropyl- methylcellulose compression-coated tablets. Pharmaceutical Development and Technology, 12(2), 203-210.

[11] Fukui, E., Uemura, K. and Kobayashi, M. (2000) Studies on applicability of press-coated tablets using hydroxypropylcellulose (HPC) in the outer shell for timedrelease preparations. Journal of Controlled Release, 68(2), 215-223.

[12] Matsuo, M., Arimori, K., Nakamura, C. and Nakano, M. (1996) Delayed-release tablets using hydroxyethylcellulose as a gel-forming matrix. International Journal of Pharmaceutics, 138(2), 225-235.

[13] Sawada, T., Kondo, H., Nakashima, H., Sako, K. and Hayashi, M. (2004) Time-release compression-coated core tablet containing nifedipine for chronopharmacotherapy. International Journal of Pharmaceutics, 280(1-2), 103-111.

[14] Ugurlu, T., Turkoglu, M., Gurer, U.S. and Akarsu, B.G. (2007) Colonic delivery of compression coated nisin tablets using pectin/HPMC polymer mixture. European Journal of Pharmaceutics and Biopharmaceutics, 67(1), 202-210.

[15] Lin, S.Y., Li, M.J. and Lin, K.H. (2004) Hydrophilic excipients modulate the time lag of time-controlled disintegrating press-coated tablets. AAPS PharmSciTech, 5(4), Article 54.

[16] Fukui, E., Miyamura, N., Yoneyama, T. and Kobayashi, M. (2001) Drug release from and mechanical properties of press-coated tablets with hydroxypropylmethylcellulose acetate succinate and plasticizers in the outer shell. International Journal of Pharmaceutics, 217(1-2), 33-43.

[17] Fukui, E., Miyamura, N. and Kobayashi, M. (2001) Effect of magnesium stearate or calcium stearate as additives on dissolution profiles of diltiazem hydrochloride from press-coated tablets with hydroxypropylmethylcellulose acetate succinate in the outer shell. International Journal of Pharmaceutics, 216(1-2), 137-146.

[18] Narendra, C., Srinath M.S. and Rao, B.P. (2005) Development of three layered buccal compact containing metoprolol tartrate by statistical optimization technique. International Journal of Pharmaceutics, 304(1-2), 102114.

[19] Lewis, G.A., Mathieu, D. and Phan-Tan-Luu, R. (1999) Pharmaceutical experimental design. Marcel Dekker, New York.

[20] Li, S., Lin, S., Daggy, B.P., Mirchandani, H.L. and Chein, Y.W. (2003) Effect of HPMC and carbopol on the release and floating properties of gastric floating drug delivery system using factorial design. International Journal of Pharmaceutics, 253(1-2), 13-22.

[21] Nouranian, S., Garambi, H. and Mohammadi, N. (2007) Taguchi-based optimization of adhesion of polyurethane to plasticized poly (vinyl chloride) in synthetic leather. Journal of Adhesion Science and Technology, 21(8), 705724.

[22] Conti, S., Maggia, L., Segalea, L., Machiste, E.O., Conte, U., Grenier, P. and Vergnault, G. (2007) Matrices containing NaCMC and HPMC 1. Dissolution performance characterization. International Journal of Pharmaceutics, 333(1-2), 136-142.

[23] Matsuo, M., Nakamura, C., Arimori, K. and Nakano, M. (1995) Evaluation of hydroxyethylcellulose as a hydrophilic swellable material for delayed release tablets. 
Chemical \& Pharmaceutical Bulletin, 43(2), 311-314.

[24] Mahato, R.I. (2005) Biomaterials for delivery and targeting of proteins and nucleic acids. CRC Press, Florida.

[25] Enayatifard, R., Saeedi, M., Akbari, J. and Tabatabaee, Y.H. (2009) Effect of hydroxypropylmethylcellulose and ethylcellulose content on release profile and kinetics of diltiazem hcl from matrices. Tropical Journal of Pharmaceutical Research, 8(5), 425-432.

[26] Roy, D.S. and Rohera, B.D. (2002) Comparative evaluation of rate of hydration and matrix erosion of HEC and HPC and study of drug release from their matrices. European Journal of Pharmaceutical Sciences, 16(3), 193-199.

[27] Hilton, A.K. and Deasy, P.B. (1992) In vitro and in vivo evaluation of an oral sustained-release floating dosage form of amoxycillin trihydrate. International Journal of Pharmaceutics, 86(1), 79-88.

[28] Durig, T. and Fassihi, R. (1997) Mechanistic evaluation of binary effects of magnesium stearate and talc as dissolution retardants at $85 \%$ drug loading in an experimental extended-release formulation. Journal of Pharmaceu- tical Sciences, 86(10), 1092-1098.

[29] Minarro, M., Garcia-Montoya, E. and Sune-Negre, J.M. (2001) Study of formulation parameters by factorial design in metoprolol tartrate matrix systems. Drug Development and Industrial Pharmacy, 27(9), 965-973.

[30] Narendra, C., Srinath, M.S. and Moin, A. (2008) Study the effect of formulation variables on in vitro floating time and release properties of floating drug delivery system by statistical optimization technique. Chemical Industry \& Chemical Engineering Quarterly, 14, 17-26.

[31] Sanchez-Lafuente, C., Furlanetto, S., Fernandez-Arevalo, M., Alvarez-Fuentes, J., Rabasco, A.M., Faucci, T., Pinzauti, S. and Mura, P. (2002) Didanosine extended- release matrix tablets: Optimization of formulation variables using statistical experimental design. International Journal of Pharmaceutics, 237(1-2), 107-118.

[32] Kuo, C.F.J. and Wu, Y.-S. (2006) Optimization of the film coating process for polymer blends by the greybased Taguchi method. International Journal of Advanced Manufacturing Technology, 27(5-6), 525-530. 